\title{
Outlook for the low birthweight baby-then and now
}

The infant weighing $2000 \mathrm{~g}$ and less at birth will today with few exceptions be nursed in some sort of special unit. If he is ill he may be transferred to a regional centre where he becomes the central focus of complex machinery. This is designed to support entirely or otherwise aid or monitor his respiration, to control his thermal environment, to record his heart beat, arterial oxygen tension, and blood pressure continuously and, at its most sophisticated, to store the entire output of data along with the results of various blood tests on magnetic tape. On page 820 of this issue, Douglas and Gear report follow-up results in adolescence of a group of infants weighing $2000 \mathrm{~g}$ and less, born 30 years ago, who were nursed without such help, many of them at home. There were 163 infants of this weight from a total of 12468 legitimate, singleton births in the first week of March 1946, in England, Scotland, and Wales. 80 survived to the age of 18 , and the report deals with 69 of them, 11 having either emigrated or been lost to initial follow-up for other reasons. Each was carefully matched with one of the cohort weighing more than $2500 \mathrm{~g}$ for sex, birth order, maternal age, social group, and degree of crowding in the home.

The low birthweight (LBW) group showed no significant excess of severe physical, mental, or behavioural handicaps compared with these controls. Children were defined as having such handicaps if they were in long stay institutions or at special schools, had a condition that limited activity or involved prolonged medical care, had more than one fit between birth and 15 years, or scored on more than one occasion more than two standard deviations below the mean for the whole survey population on tests for ability and attainment at 8,11 , or 15 years. The loss of 11 children from the original 80 does not compromise these results for it is known that none of them had a serious physical or mental handicap. After standardization to give an IQ equivalent, mean test scores of the LBW group were 7 points below those for controls, but these differences did not achieve statistical significance. The mean score of the controls was in turn 3 points below that for the entire cohort. Despite the very careful initial matching of controls, Douglas was later forced to conclude that parents of the LBW infants tended to provide a lower standard of care, and to show less interest in their children's school progress than did parents of the controls. Moreover, the home circumstances of the controls had improved more substantially 11 years after their birth than had those of the LBW group (Douglas, 1960).

There are several other important aspects of this report. Long hospital stay after birth was not associated with behaviour or learning problems in adolescence. There were no cases of retrolental fibroplasia, in contrast to what happened a few years later. We know that this condition is still seen in this country (Mushin, 1974), in Sweden (Svedbergh and Linstedt, 1973), and in the United States (Alden et al., 1972), though there was an immediate fall in prevalence when the association with oxygen therapy was first established. Cerebral palsy too does not appear as an important cause of handicap among survivors, whereas Lubchenco et al. (1963) were to report spastic diplegia in 35\% of children who had weighed $<1500 \mathrm{~g}$ at birth some 11-14 years later. A proportion of the survivors of neonatal mechanical ventilation in recent years tend to have other forms of cerebral palsy as frequently as spastic diplegia, and to be moderately or severely, rather than mildly handicapped (Fitzhardinge et al., 1976; Marriage and Davies, 1977). Survival rates have of course been increasing slowly but steadily since 1946. During the week of the survey, the neonatal mortality of the LBW infants described by Douglas and Gear was $47 \%$. In 1953, the first year national figures were available by weight group, it was $39 \%$ for all infants $\leqslant 2000 \mathrm{~g}$ born in England and Wales (as opposed to that for legitimately born singletons in England, Scotland, and Wales); and in 1973, the last year for which 
figures are available, it was $28 \%$ (Alberman, 1974 , and personal communication).

Mortality statistics in infants of very low birthweight, particularly those of less than $1000 \mathrm{~g}$ are difficult to interpret because of ambiguity surrounding such terms as 'viability'. The practice of including all infants of $500 \mathrm{~g}$ and above as liveborn if a heart beat or respiratory gasp is present at birth, would perhaps give greater uniformity to such figures (Davies and Stewart, 1975). Thus it is not possible to compare present mortality rates from units which have compiled them in this way with these from the 1946 cohort or those standardized by Alberman (1974). However, if we accept that mortality of infants weighing $2000 \mathrm{~g}$ or less has fallen nationally by about $20 \%$ in the last 30 years, it is clear that later morbidity will also have to have fallen by a considerable extent if actual numbers of handicapped LBW children are not to increase; it seems doubtful if this is so at present.

If Douglas and Gear's estimate of the normality of the children lost to conventional follow-up is accepted, $12 / 80(15 \%)$ of their LBW survivors had 'severe' physical, mental, or behavioural handicaps as defined. However, all but one of the 12 were in gainful employment at 18 years, which may give a better idea of their potential as citizens. All the handicapped were in the birthweight subgroup 1501-2000 g; there were no survivors of less than $1000 \mathrm{~g}$, and the 14 who had weighed $1000-1500 \mathrm{~g}$ were normal.

Follow-up studies of LBW infants nursed in the neonatal intensive care units of the last decade are appearing from many parts of the world, but it seems most relevant to mention only the three British surveys here. They come from the Simpson Memorial Maternity Pavilion in Edinburgh, and from the University College and Hammersmith Hospitals in London and include multiple as well as singleton births. These three units do not serve identical populations. Thus Drillien (1972) has pointed out that compared with the University College Hospital sample reported by Rawlings et al. (1971), two and a half times as many small-fordates (SFD) infants of the same birthweight had been born during the same period in Edinburgh. An unusual social class distribution at University College Hospital may partly explain this for $38 \cdot 8 \%$ of survivors reported by Stewart and Reynolds (1974) belonged to social classes I and II, compared with $17.5 \%$ at Hammersmith Hospital (Davies and Tizard, 1975) where in turn the SFD population is more akin to that of Edinburgh. Drillien (1972) judged $9.6 \%$ of 283 Edinburgh infants born 196671 and weighing $2000 \mathrm{~g}$ and less to be severely handicapped between 1 and 3 years of age. The figure was $13 \cdot 7 \%$ for those $\leqslant 1500 \mathrm{~g}$ and $7 \cdot 7 \%$ for those of 1501-2000 g. In practically all the disability was either singly, or in association, some form of cerebral palsy, hydrocephalus, or epilepsy. Reports from the two London referral units deal with infants of very low birthweight$1500 \mathrm{~g}$ and less. Stewart and Reynolds (1974) report physical and mental handicap at 2-7 years in $9.5 \%$ of 95 such infants cared for at University College Hospital between 1966 and 1970. At Hammersmith Hospital $18 \cdot 3 \%$ of 165 children born 1961-70 were considered handicapped (IQ less than 70, major and minor neurological disability, moderate to severe visual or hearing defect) between 4 and 14 years of age (Davies, 1976). At both these hospitals handicap rates for those $<1000 \mathrm{~g}$ are no greater than their figures for those $\leqslant 1500 \mathrm{~g}$ (Stewart et al., 1977; unpublished results). However, many of the children referred to in all three studies are still very young, estimates of handicap must be taken as provisional, and if this country's present social and economic circumstances persist, tomorrow's handicapped school leavers may not find themselves as readily employable as in 1964.

There have been three excellent perinatal surveys here in the last 30 years, beginning with the 1946 cohort. Criticisms of such studies often voiced are that so many people are involved in collecting data that exact standardization of tests and clinical examinations may be impossible to impose, and that numbers of special groups within the cohort are invariably small. One feels for instance that it should be possible to define neurological handicap in adolescence with greater precision than 'left shoulder droops, left foot drags' (Table II, Douglas and Gear), though it may be permissible to use terms like 'clumsy' to describe much younger children who run or walk awkwardly, and cannot hop on one foot or walk toe-to-heel along a straight line. Regarding small numbers, the authors point out that population studies nevertheless 'show the true dimensions of problems whose importance may have been exaggerated by the investigation of highly selected groups'. It is often forgotten that the generally poor follow-up results in LBW infants born in the 1950s (Lubchenco et al., 1963; Drillien, 1964; McDonald, 1967; Wright et al., 1972) were to a large extent associated with iatrogenic disease; and that later prospects for the LBW had already improved considerably (Davies and Russell, 1968) before modern electronic gadgetry was applied to their early care. All would agree that the technological approach to the newborn has 
contributed enormously to our knowledge of his pathophysiology, and in turn to falling mortality figures. In uninformed hands, however, it can be frankly dangerous. This 1946 survey should provide us with a much better yardstick by which to measure success or otherwise in terms of later potential of the individual, however uncomfortable it may be to do so.

Pamela A. Davies Department of Paediatrics and Neonatal Medicine, Hammersmith Hospital, Du Cane Road, London W12 OHS.

\section{REFERENCES}

Alberman, E. (1974). Stillbirths and neonatal mortality in England and Wales by birthweight, 1953-71. Health Trends, 6, 14 .

Alden, E. R., Mandelkorn, T., Woodrum, D. E., Wennberg, R. P., Parks, C. R., and Hodson, W. A. (1972). Morbidity and mortality of infants weighing less than 1,000 grams in an intensive care nursery. Pediatrics, 50, 40.

Davies, P. A. (1976). Infants of very low birthweight. An appraisal of some aspects of their present neonatal care and of their later prognosis. Recent Advances in Paediatrics. Ed. by D. Hull. Churchill Livingstone, Edinburgh, London, and New York.

Davies, P. A., and Russell, H. (1968). Later progress of 100 infants weighing 1,000 to $2,000 \mathrm{~g}$. at birth fed immediately with breast milk. Developmental Medicine and Child Neurology, 10, 725.

Davies, P. A., and Stewart, A. L. (1975). Low-birth-weight infants: neurological sequelae and later intelligence. British Medical Bulletin, 31, 85 .

Davies, P. A., and Tizard, J. P. M. (1975). Very low birthweight and subsequent neurological defect (with special reference to spastic diplegia). Developmental Medicine and Child Neurology, $17,3$.

Douglas, J. W. B. (1960). 'Premature' children at primary schools. British Medical fournal, 1, 1008.

Drillien, C. M. (1964). The Growth and Development of the Prematurely Born Infant. Livingstone, Edinburgh.

Drillien, C. M. (1972). Aetiology and outcome in low-birthweight infants. Developmental Medicine and Child Neurology, 14, 563.

Fitzhardinge, P. M., Pape, K., Arstikaitis, M., Boyle, M., Ashby, S., Rowley, A., Netley, C., and Swyer, P. R. (1976). Mechanical ventilation of infants less than $1,501 \mathrm{gm}$. birthweight: health growth, and neurologic sequelae. Fournal of Pediatrics, 88, 531.

Lubchenco, L. O., Horner, F. A., Reed, L. H., Hix, I. E., Metcalf, D., Cohig, R., Elliott, H. C., and Bourg, M. (1963). Sequelae of premature birth. Evaluation of premature infants of low birth weights at ten years of age. American fournal of Diseases of Children, 106, 101.

McDonald, A. (1967). Children of Very Low Birth Weight. Heinemann Medical, London.

Marriage, K. J., and Davies, P. A. (1977). Neurological sequelae in children surviving mechanical ventilation in the neonatal period. Archives of Disease in Childhood (in press).

Mushin, A. (1974). Retinopathy of prematurity-a disease of increasing incidence? Transactions of the Ophthalmological Societies of the United Kingdom, 94, 251.

Rawlings, G., Reynolds, E. O. R., Stewart, A., and Strang, L. B. (1971). Changing prognosis for infants of very low birth weight. Lancet, 1, 516.

Stewart, A. L., and Reynolds, E. O. R. (1974). Improved prognosis for infants of very low birthweight. Pediatrics, 54, 724.

Stewart, A. L., Turcan, D. M., Rawlings, G., and Reynolds, E. O. R. (1977). Prognosis for infants weighing $1000 \mathrm{~g}$ or less at birth. Archives of Disease in Childhood (in press).

Svedbergh, B., and Lindstedt, E. (1973). Retrolental fibroplasia in Sweden. General survey and selected study on patients born in 1960-1966. Acta Paediatrica Scandinavica, 62, 458.

Wright, F. H., Blough, R. R., Chamberlin, A., Ernest, T., Halstead, W. C., Meier, P., Moore, R. Y., Naunton, R. F., and Newell, F. W. (1972). A controlled follow-up study of small prematures born from 1952 through 1956. American fournal of Diseases of Children, 124, 506. 